\title{
HUMAN INTERFERENCES TO THE ENVIRONMENT, CONSEQUENCES AND CARE
}

\author{
Lampropoulou P. ${ }^{1}$, Tzevelekou Th. ${ }^{2}$, Papamantellos D. ${ }^{2}$, Stivanakis V³, \\ Papaefthymiou S. ${ }^{2}$ \\ ${ }^{1}$ University of Patras, Department of Geology, Section of Earth Materials, 26500 Patras, Greece, p.lam- \\ propoulou@upatras.gr \\ ${ }^{2}$ Hellenic Center of Metals Research S.A.(ELKEME), 17778 Tavros, Athens/Greece, \\ dpapamantellos@elkeme.vionet.gr,ftzevelekou@elkeme.vionet.gr,spapaefthymiou@elkeme.vionet.gr \\ ${ }^{3}$ University of Patras, Department of Chemical Engineers, Laboratory of Metallurgy, \\ 26500 Patras, Greece \\ vstivanakis@chemeng.upatras.gr
}

\begin{abstract}
The need to restore the relationship of mankind with the environment led to the designation of measures, terms and processes worldwide for the prevention or reduction to the highest possible degree of the negative consequences to the environment ensuring a high level of protection of human health and the environment. It is general ascertainment that there is a big lack of objective information in Greece regarding the possibilities of modern science and technology for the treatment of Solid Industrial Wastes (SIW), Municipal Solid Wastes (MSW) and biological Sewage Treatment Plants (STP) products safely for the public health and the environment. In Greece the most significant sources of SIW are the big exploitations of "Mineral Ores". On the contrary, the cement industries provide an important way out for the consumption of SIW like fly ash, red mud, et. A big percentage of the total amount of produced alloys of iron, copper, zinc and aluminium do not use "Mineral Resources" as raw materials but recycle scrap metals. At the end, the successful results of pyrometallurgical production of final products by SIW as well as the results of the production of new friendly to the environment and high technology refractory materials are given in this work.
\end{abstract}

Key words: environment, human interferences, solid industrial and municipal wastes, consumption of wastes.

\section{Introduction}

The current image of Greece regarding the management of Solid Industrial Wastes (SIW) and especially of the Municipal Solid Wastes (MSW) as well as of the products resulting from the biological Sewage Treatment Plants (STP) is falling behind the European Standards. The hierarchy in waste prevention and management as set in EU Waste Framework Directive (EU Directive 2008/98/EC) should lie on (i) prevention, (ii) preparation for reuse, (iii) recycling, (iv) other recovery (i.e. energy recovery) and (v) disposal. Modern technologies based on Best Available Techniques and on the results of relative scientific studies should be implemented. 


\section{Municipal Solid Wastes (MSW)}

The present Greek MSW production is in the range of $\sim 4.5 \mathrm{mil} . \mathrm{t} / \mathrm{y}$. The main characteristic of MSW management in Greece is that over 90\% results in landfilling as presented in Fig. 1 (Papamantellos et al 2005), and in more than 1300 cases landfilling has been preformed illegally (2005 data). Only in Attica, within the next decade the handling of predicted 35-45 mil. tons municipal wastes, taking a production of 7000t/d MSW, will require 7-8 additional landfill sites of $500.000 \mathrm{~m}^{2}$ area and $20 \mathrm{~m}$ height each, while the operation of the already approved landfilling areas in Keratea and Grammatiko have been blocked!

Greece "keeps the negative record" in Municipal Solid Wastes Landfilling and the last place in the energy exploitation of their content in modern WTE (Waste to Energy) plants, Fig. 2, according to 2005 data (Papamantellos, 2007).

This situation of MSW mismanagement, which does not conform to the EU environmental legislation, resulted in sensitive penalties posed by the EU. The current status requires drastic measures under one political and decision making centre ready to adapt and implement modern and efficient techniques. The current decision decentralization to the regions and the municipalities leads to polyphony and endless discussions about the most suitable technologies without implementation.

For solving the hot environmental issues of the Greek Society quick cooperation between involved Ministries is absolutely necessary. Creation of a task force from the Ministers of Environment, Economy, Interior and Development is here proposed. Target of this task force would be the foun-dation of an independent Authority for determining strategies of Municipal-, Hazardous-, Indus-trial- Waste - Management and landscape rehabilitation. This independent Authority should decide about technologies to be applied, the structure of the cooperating involved parties (private, state, municipal, etc), their funding including cost-benefit analyses and optimum for each case operation units. This independent Authority should be responsible for making the final decision about the needed measures and actions for the environmental problems under consideration and should assist the funding of the projects, taking also EU grants into consideration. It also could provide techni-cal assistance for the preparation, publication and evaluation of all kind of tenders (public, pri-vate). Furthermore, it will supervise the implementation of the relevant projects keeping the time scheduling. In case of landscape rehabilitation the Authority will provide the legal and environ-mental framework and, then, supervise the execution of the rehabilitation actions taken by private companies after private tender on their responsibility. A very essential task of this independent Authority, in cooperation with Universities, NGOs, etc should be the information of the Society regarding environmental safe MSW management measures. Relevant example of such an inde-pendent Authority's successful activity was the Organization Committee "Athens 2004".

As an example, the public opinion should be informed that modern applied technologies allow nowadays the safe and clean operation of a WTE unit as shown in Figs. 3, 4. Very impressive is the high volume of gas cleaning systems installation, Fig. 3, so that the gas outlet is completely clean and air pollution is prevented especially from dioxins. A characteristic example of WTE installation is the one operating successfully in Brescia, Italy, Fig. 4, serving the needs of 500.000 people. The sewage sludge from the waste water treatment plant of the city is also incinerated in the plant. The unit produces $50 \mathrm{MW}$ and the producing steam is used for central thermal supply in the city (Papamantellos et al., 2009). The Brescia WTE plant was placed on the area of the old landfill site of the city, which has been rehabilitated. 


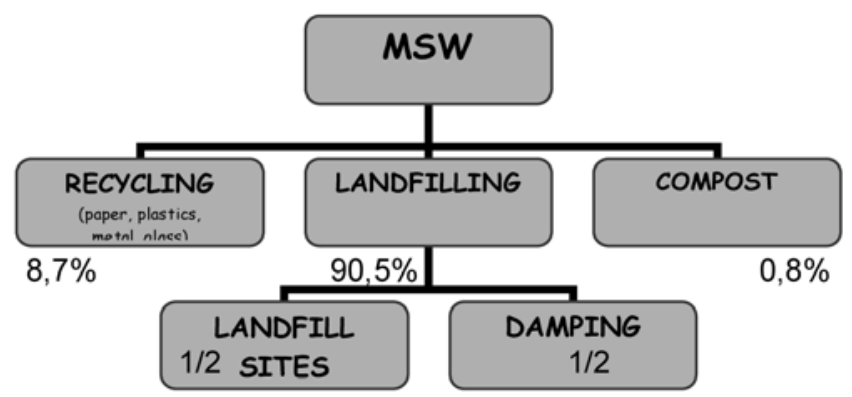

Fig. 1: Breakdown of the MSW management in Greece (Papamantellos et al., 2009).
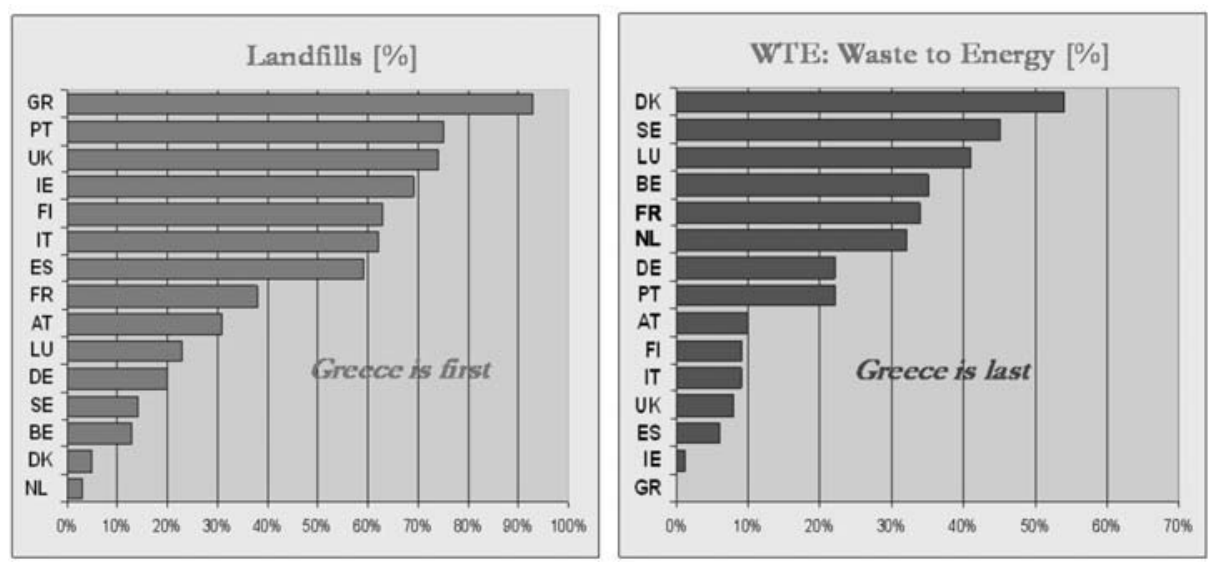

Fig. 2: Municipal Solid Wastes (MSW) management in Greece and EU, 2005 data.

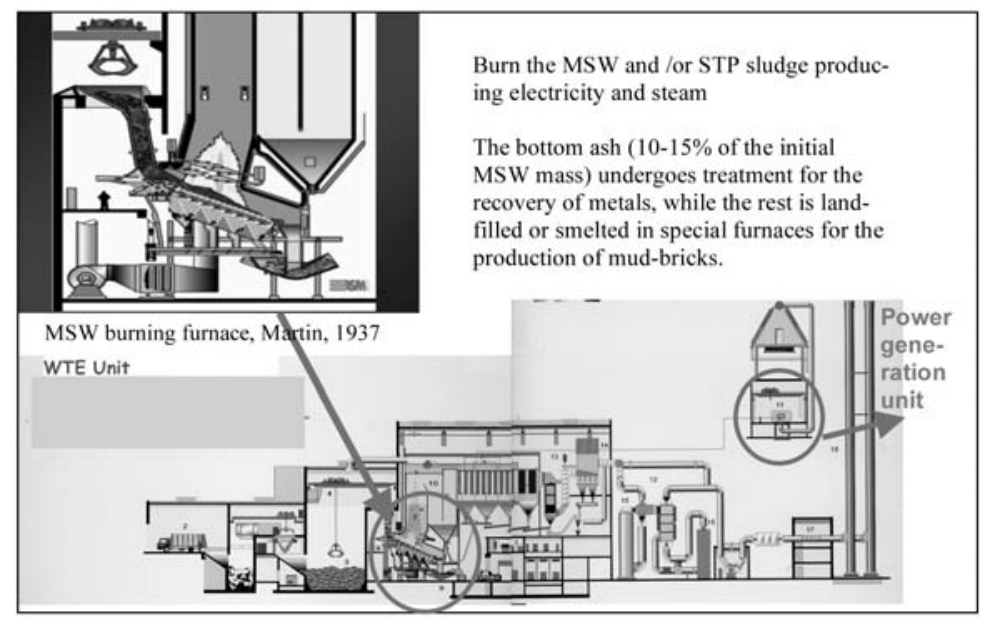

1. Central control room, 2. Tipping floor, 3.Pit, 4.Crane, 5, Feed chute, 6.MARTIN Reverse-Acting Stoker Grate, 7.Furnace, 8.MARTIN hydraulic system, 9.MARTIN ash discharger, 10. Steam Boiler, 11. Turbine-generator, 12. Flue gas treatment system, 13. Activated carbon supply, 14. Fabric Filter, 15. Counterflow spray tower scrubber, 16. DeNOx catalyst, 17. Clean gas monitoring equipment, 18. Clean gas stack

Fig. 3: WTE unit for the MSW management: feeding, burning, steam and power generation. 


\section{Solid Industrial Wastes (SIW)}

Extended open pits for exploitation of fossil fuels (lignite Figs $5 \mathrm{a}, \mathrm{b}$ ), ores (nickelferrous laterites (Figs 7a, b ), bauxite (Fig. 8), magnesites, limestone (Figs 9a,b) perlite, pumice, etc) is the biggest source of industrial solid waste in Greece. Example of open pit rehabilitation is shown in Fig. 5b including the reforestation and lake creation forming a refreshment area close to urban environment.

The development of the total lignite production $(\mathrm{t} / \mathrm{y})$ and the total excavations has been proliferated since the beginning of the mine operation till the year of 2006 (Figs 6a, b) [Papamantellos, 2007].

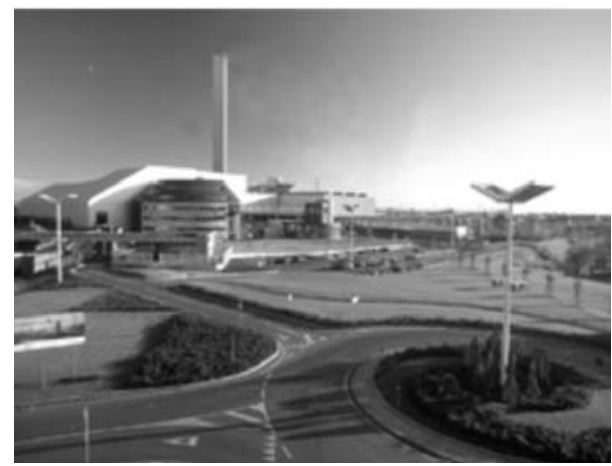

Fig. 4: WTE facility in Brescia.

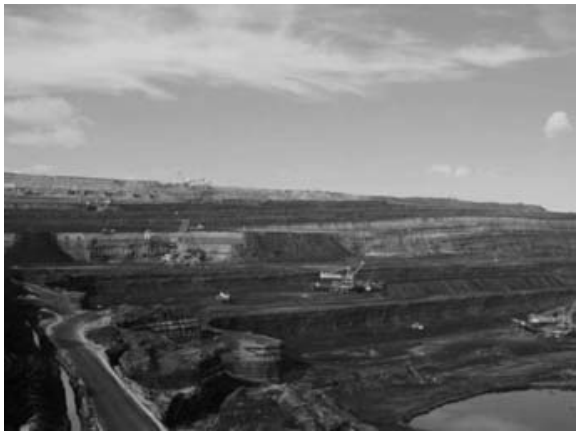

Fig. 5a: PPC Lignite mine for el. power generation.

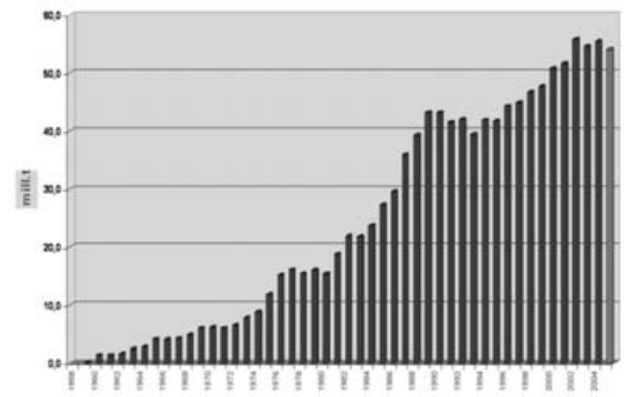

Fig. 6a: Development of lignite production.

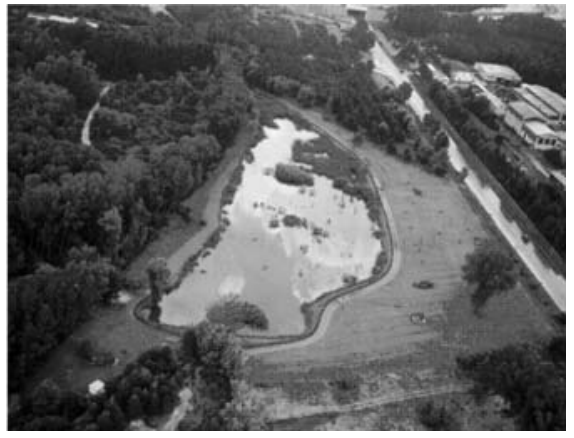

Fig. 5b: Environmental rehabilitation of open pit

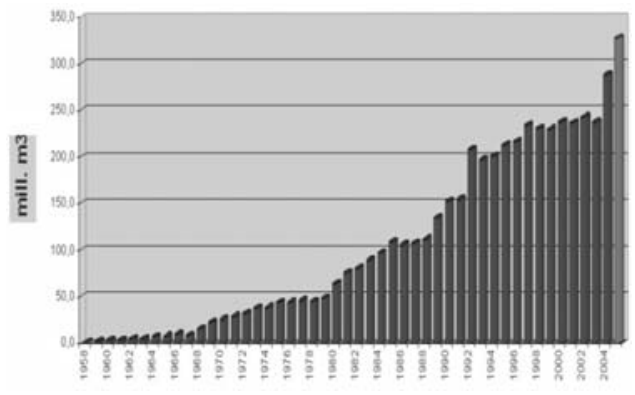

Fig. 6b: Development of excavations of lignite open pits. 


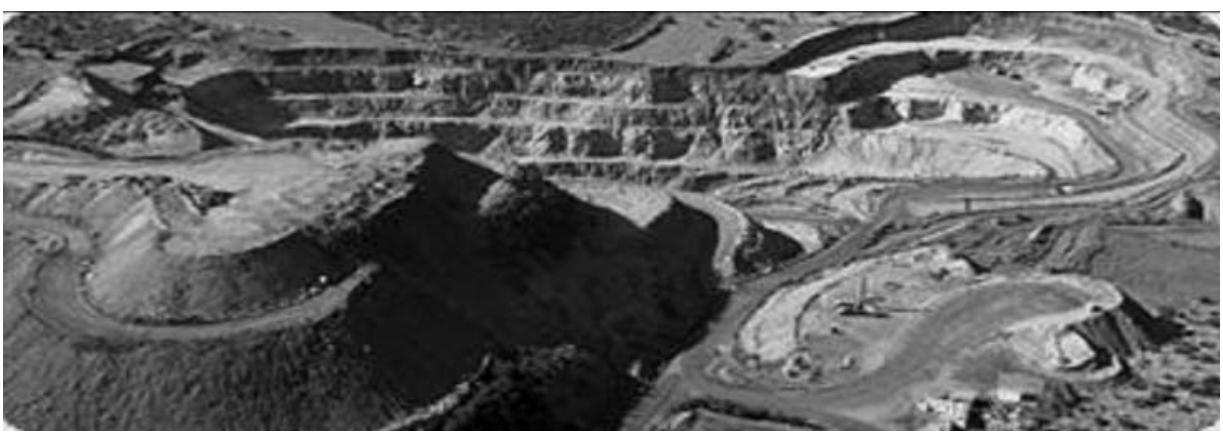

Fig. 7a: Nickelferrous laterite mine of LARCO for the production of ferronickel. For the production of 100.000 t/y FeNi 20, 2.2 mil.t /y of ore are needed.

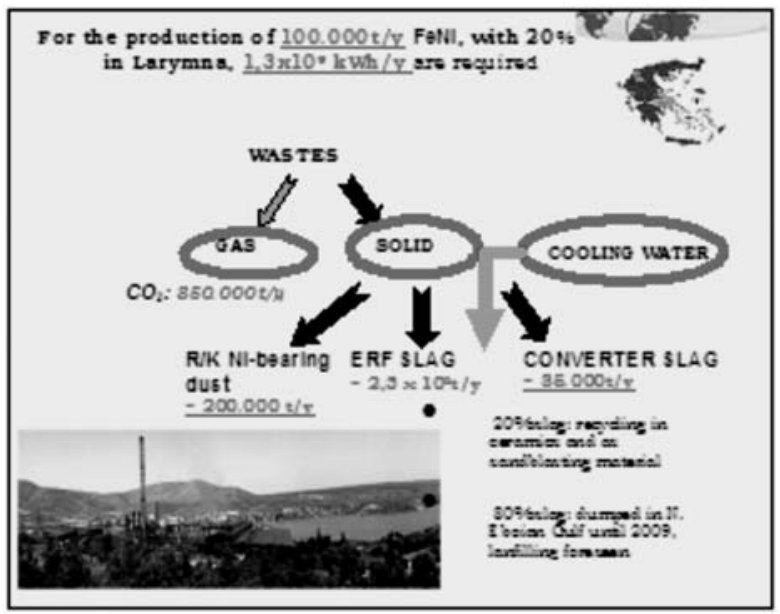

Fig. 7b: The waste (solid, liquid and gas) generation associated with the production of $100.000 \mathrm{t} / \mathrm{y}$ ferronickel, $20 \% \mathrm{Ni}$, FeNi20 at Larymna.

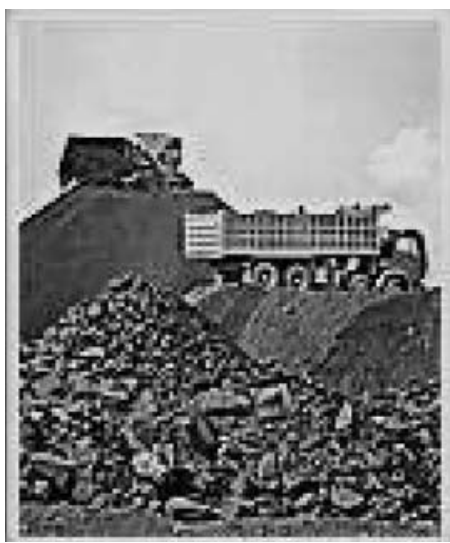

Fig. 8: Bauxite mine of ALUMINIUM OF GREECE for the production of alumina and primary aluminium. From $1,000,000 \mathrm{t} / \mathrm{y}$ bauxite are produced 450,000 t/y alumina, 170,000 t/y aluminium and 650,000 t/y red mud (SIW). 

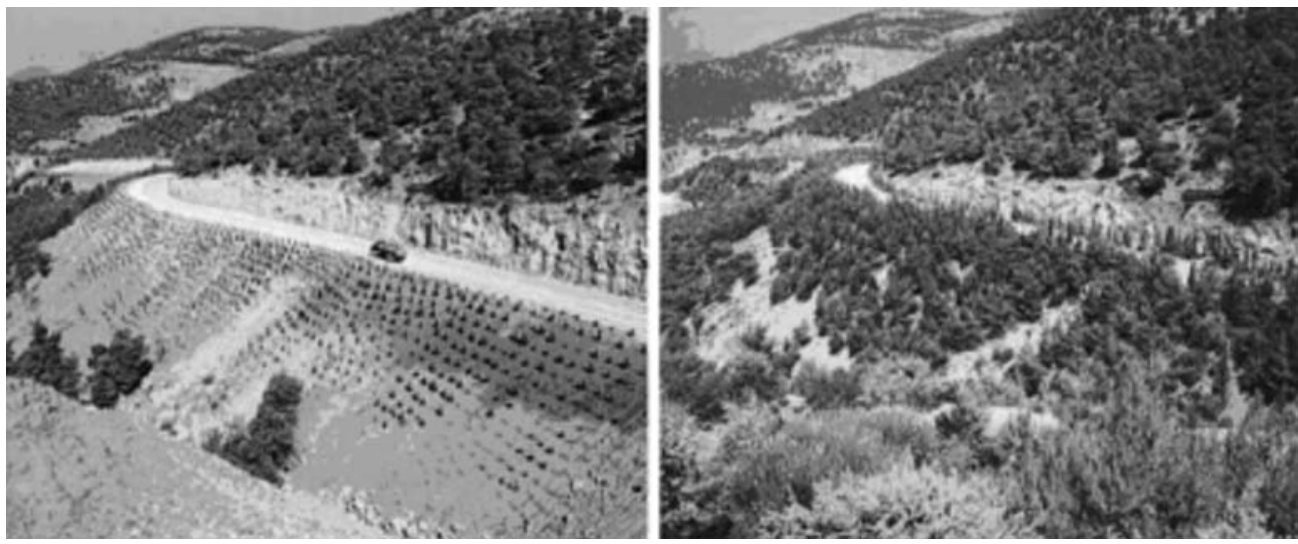

Fig.9a, b: Early and late stage of limestone open pit rehabilitation (Titan, 2009).

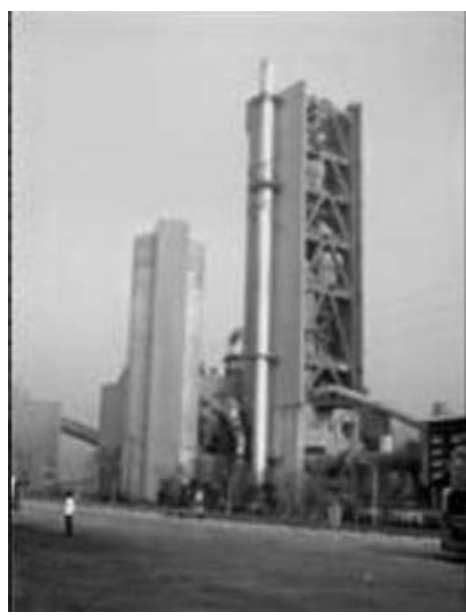

Fig. 10: Cement Industry.

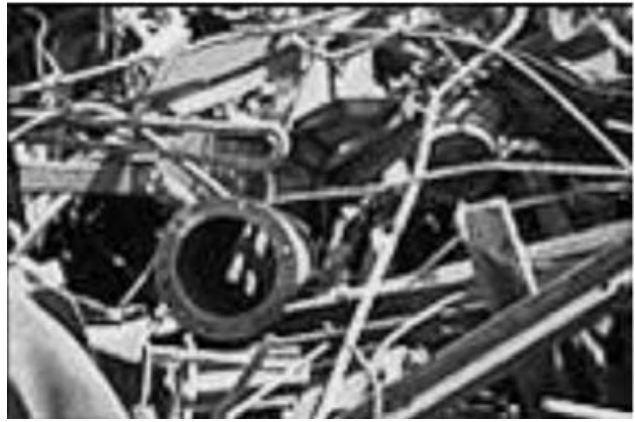

Fig. 11: Scrap metals used as raw materials for the production of new metallic products.

It is evident that the reforestation efforts of open pits excavations as well as of burned forests according to international experience should be combined not only with the plantation of trees but also with bushes adjusted to the environment to be rehabilitated. The use of biological STP sludge as well as fly ash of the lignite production could be very helpful in the above efforts as humus and trace elements carriers respectively.

\section{Industrial utilization of SIW}

The cement industries provide an important way out for the consumption of SIW like fly ash, red mud, etc incorporating them in their high temperature industrial production, Fig. 10. The metallurgical industries in Greece that produce steel, alloys of copper, zinc and aluminium do not use "Mineral Resources" as raw materials but recycle scrap metals which are actually wastes of the consumer society and/or of other small or large scale industrial facilities (Fig. 11). 
Table 1. Composition of Plyttalia sludge compared to lignite (Papamantellos et al 2005).

\begin{tabular}{|l|c|c|c|}
\hline \multirow{2}{*}{} & \multicolumn{2}{|c|}{ Psyttalia sludge } & Lignite of Megalopolis \\
\cline { 2 - 4 } & Dewatered & Dry & \\
\hline Humidity (\%) & 68 & - & 60 \\
\hline Inorganic (Ash) (\%) & 10 & $60-35$ & 14 \\
\hline Organic Matter (\%) & 21 & $40-65$ & 26 \\
\hline $\begin{array}{l}\text { Energy content } \\
\text { (kcal/kg) }\end{array}$ & $500-750$ & $2200-3200$ & 900 \\
\hline
\end{tabular}

\section{Examples of pyrometallurgical production of final products by SIW and of new friendly to the environment basic refractory materials}

Successful researches related with production of final products by solid industrial wastes as well as production of new friendly to the environment and high technology refractory materials, have been carried out by researchers in the University of Patras and these examples are referred in this work:

EXAMPLE 1: Production of alumina cement by SIW (slag from the ferronickel production). (Dourdounis, 2003).

EXAMPLE 2: Reduction smelting of SIW (E-filter R/K Ni-dust) of ferronickel production for the production of low alloyed steel grades and slagcements (Tzevelekou, 2004).

EXAMPLE 3: Utilization of solid by products resulting from lignite firing in the production of lightweight aggregates (Anagnostopoulos, 2009).

EXAMPLE 4: Production of FeNi and FeV from the reduction smelting of residues resulting from the PPC'S oil firing units for the electrical power generation (Karamoutsos, 2004).

EXAMPLE 5: Production of Greek type portland cement by using fly ash, the SIW of PPC'S lignite firing as a pozolanic material (Stivanakis, 2003).

EXAMPLE 6: Utilization of red mud, the SIW from the production of alumina for the production of bricks, tiles and as raw material in the production of cement (Pontikes, 2007).

EXAMPLE 7: Mineralogical composition and properties of basic refractories and new magnesiaspinel compositions derived from magnesite of N. Evian (Lampropoulou, 2003).

\section{The case of Psyttaleia's Biological Sewage Treatment Plant sludge}

The composition of Biological Sewage Treatment Plant sludge, like the one produced on the island of Psyttaleia, Table 1, renders it a very promising solid fuel compared to solid fossil carbonaceous fuels, as lignite, used for electrical energy production due to its high energy content. The disintegrated sludge with thermal capacity of $500-700 \mathrm{kcal} / \mathrm{kg}$ can be fired in a solid fuel fired boiler for power generation without any previous treatment. The dry sludge is fired nowadays in cement production units. In case a WTE unit existed for the management of MSW, the sludge could be easily co-fired to the unit as well. Provided that, as already mentioned, there are no such installations in Greece today, the sludge could be co-fed to one of the existing coal power plants after proper modifications of the relative units. The PPC unit No 3 in Aliveri was selected as a possible solution for co-firing the sludge 

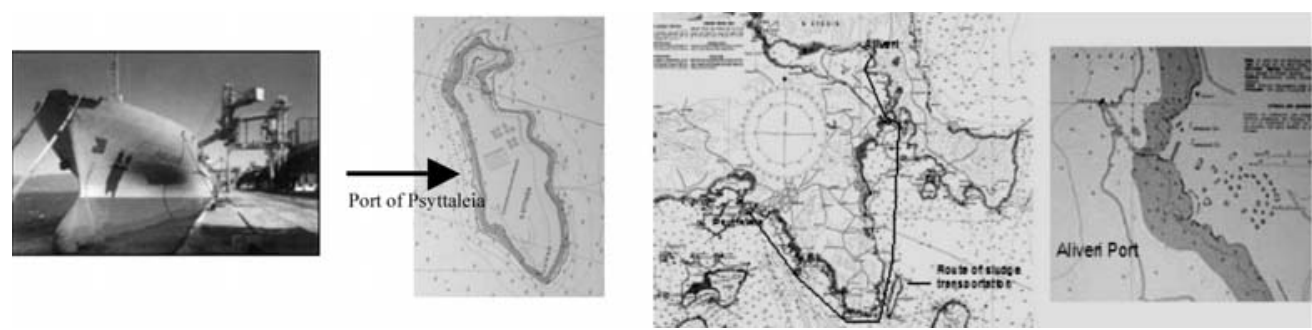

Fig. 12: Transportation of STP sludge from Psyttalia to Aliveri by special ships.

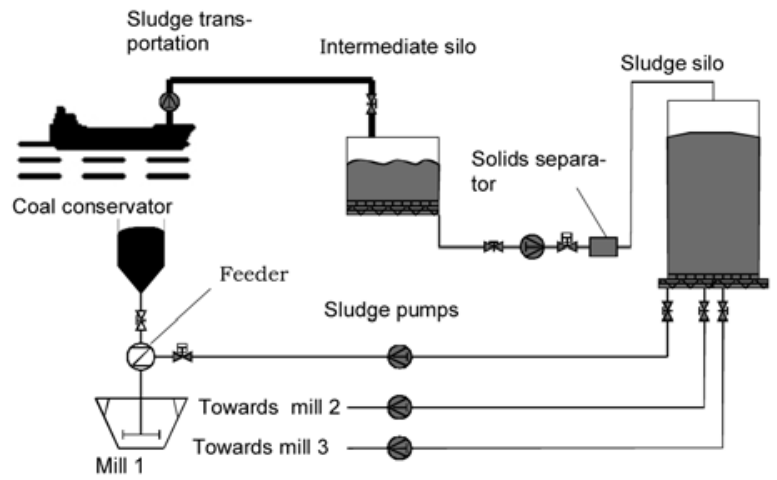

Fig. 13: Flow chart of sludge management in the power plant of PPC in Aliveri.

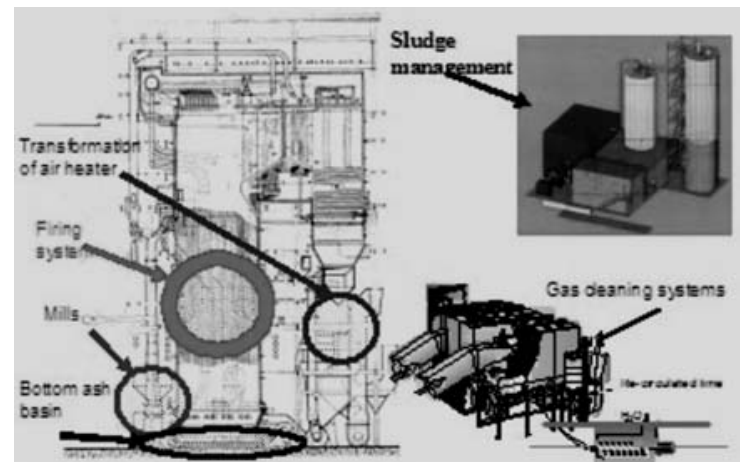

Fig. 14: Transformation areas of No 3 power plant unit in Aliveri.

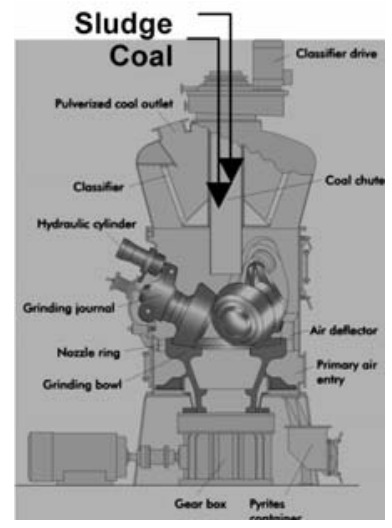

Fig. 15: Co-firing of sludge \& hard-coal in hard-coal fired power station.

with solid fuel (steam coal) due to its geographical position, which enalbes the short marine transportation $(\sim 70 \mathrm{~nm})$ of the sludge in special ships, Fig. 12, from the port of Psyttaleia to the port of Aliveri (Papamantellos et al., 2005).

Once the sludge arrived to the power plant in Aliveri, the process described in the flow chart of Fig. 13 would follow. Certain modifications of the unit would be necessary in order to co-fire the sludge as presented in Fig. 14 (Heinz et al., 2005). The transformation, gas cleaning systems and sludge drying (optional) expenses were estimated 55 mil.€, which could be depreciated in 23 years from the 
difference in the fuel cost. This proposal for Aliveri was not realized by PPC. How-ever similar transportation of the sludge and co-firing to a hard-coal fired power station placed on the coast, with maximum distance from Psyttaleia 70-130km, to be constructed in the near future could be examined. The sludge can be pneumatically charged to the hard-coal mills as shown in Fig. 15 (Heinz et al., 2005).

\section{Conclusions}

1. Pyrometallurgical methods through the utilization of high temperatures comprise an active tool in the environmental management of SIW, MSW and STP products.

2. Development of zero residue industrial production processes can be achieved by combining industrial byproducts of power generation, metals production and cement industry.

3. In a future step it will be shown that considerable benefits will result regarding $\mathrm{CO}_{2}$ emissions, energy savings, conservation of natural resources and environmental landscape protection from the adaptation of (1) to (4).

4. Closer collaboration among Municipalities, Industry, Government, Research Centres and Universities for the achievement of the aforementioned goals should be enhanced.

5. The lack in the objective information of the society must be covered regarding the possibilities of modern science and technology in the treatment of SIW, MSW and STP products safely for the public health and the environment.

6. The last two decades a lot of discussions have taken place regarding waste management in relative conferences, seminars, etc all over Greece with poor implementation results of modern waste management techniques. The current unsatisfactory situation requires drastic measures under one independent political and decision making umbrella for the whole country. The creation of a task force from the Ministers of Environment, Economy, Interior and Development is proposed with target the foundation of an independent Authority for managing Municipal, hazardous, industrial wastes and landscape rehabilitation.

7. This independent Authority should decide about the optimum technologies to be applied for MSW management, the structure of the cooperating involved parties (private, state, municipal, etc), their funding including cost-benefit analyses and optimum for each case operation units. The Authority should be responsible for making the final decision about the needed measures and actions for the environmental problems under consideration and should assist the funding of the projects, taking also EU grants into consideration. In addition, could provide technical assistance for the preparation, publication and evaluation of all kind of tenders (public, private).

8. Furthermore, this Authority will supervise the implementation of the relevant projects keeping the time scheduling. In case of landscape rehabilitation it will provide the legal and environmental framework and supervise the execution of the rehabilitation actions taken by private companies.

9. A very essential task of this independent Authority, in cooperation with Universities, NGOs, etc should be the information of the Society regarding environmental safe MSW management measures.

\section{Acknowledgments}

The authors would like to thank the Director of the Earth Engineering Centre of Columbia University, Prof. N. J. Themelis and the President of THERMOGON Mr. N. Mitsos for providing important data for the performance of the relevant studies. 


\section{References}

Anagnostopoulos I., 2009. Utilization of solid by products resulting from lignite firing in the production of lightweight aggegates. Thesis, University of Patras.

Directive 2008/98/EC of the European Parliament and of the Council of 19 November 2008 on waste and repealing certain Directives.

Dourdounis E., 2003. Production of alumina cement by SIW. Thesis, University of Patras.

Heinz G., H. Brueggemann and B. Svenson of ALSTOM POWER BOILERS GmbH, Stuttgart and Vaxjo, "Private communication", 2005.

Karamoutsos S., 2004. Production of FeNi and FeV from the reduction smelting of residues resulting from the PPC'S oil firing units for the electrical power generation. Thesis, University of Patras.

Lampropoulou P., 2003. Mineralogical composition and properties of basic refractories and new magnesia-spinel compositions derived from magnesite of N. Evian. Thesis, University of Patras.

Papamantellos D.C., Papandreou N. A., Papaefthymiou S. A., Tzevelekou T. V.: Proposal for Recycling and Energy Usage of Municipal Wastes in Greece, [in] Proc. of ISWA APESB "turing waste into ideas" International Conference, Lisbon 12.-15.10.2009.

Papamantellos D. C., Themelis N. J., Tzevelekou Th., Karamoutsos S. "Proposal for Waste to Energy implementation in Western Greece", Solid Waste Management in Western Greece Prefecture Conference, Patras, 25/02/2005.

Papamantellos D.C. "At the edge of renewable energy sources", $2^{\text {nd }}$ National Conference of Mechanical and Electrical Engineers, 18/05/2007, Greece.

Papamantellos D.C., "Metallurgy and wastes - Metallic alloys, oxidic materials and energy" $3^{\text {rd }}$ National Conference on Metallic Materials, Patras, 5-6 Dec. 2007.

Papamantellos D.C., Heinz G., H. Brueggemann and B. Svenson in cooperation with S. Karamoutsos and Th. Tzevelekou "Proposal for energy exploitation of Psyttaleia sludge by means of co-firing with steam coal", submitted to the Greek Ministries of Environment, Development in December 2004 and PPC in March 2005.

Pontikes I., 2007. Utilization of red mud, the SIW from the production of alumina for the production of bricks, tiles and as raw material in the production of cement. Thesis, Univ.of Patras.

Stivanakis V., 2003. Production of Greek type Portland cement by using fly ash, the SIW of PPC'S lignite firing as a pozolanic material. Thesis, University of Patras.

Titan, Publ. Issue 110, 2009, URL: http:/www.titan.gr/UserFiles/File/titanes/issue110/26-27.pdf.

Tzevelekou Th., 2004. Development of a process for recycling and producing new materials by reduction smelting of gas cleaning systems dusts from the ferronickel industry. Thesis, University of Patras. 